\title{
RESEARCH
}

\section{Expedited transfer for primary percutaneous coronary intervention: a program evaluation}

\section{Jacobus S. de Villiers, Todd Anderson, James D. McMeekin, Raymond C.M. Leung, Mouhieddin Traboulsi, for the Foothills Interventional Cardiology Service and the Calgary STEMI QIHI group}

$\infty$

See related article page 1843

\section{ABSTRACT}

Background: A shorter time from symptom onset to reperfusion is associated with improved outcomes for patients with ST-segment elevation myocardial infarction (MI). Primary percutaneous coronary intervention is a favourable method of reperfusion if performed effectively and expeditiously. We sought to evaluate the impact of an expedited pre-hospital diagnosis and transfer pathway developed by a multidisciplinary team on the door-to-balloon time in a large urban community.

Methods: We included all patients with ST-segment elevation MI who presented within 12 hours after symptom onset and who sought medical attention through Emergency Medical Services within the boundaries of the city of Calgary in the 16 months following the introduction of the pathway in June 2004. The primary aim was to determine the proportion of patients who received percutaneous coronary intervention within the recommended door-to-balloon time of 90 minutes.

Results: The $35^{8}$ patients ( 268 men) in the study cohort had a mean age of 63.2 (standard deviation 12.7 ) years; 140 (39.1\%) had an anterior $\mathrm{MI}$; and 23 (6.4\%) had cardiogenic shock. The introduction of the pathway resulted in a median door-to-balloon time of 62 (interquartile range 45-84) minutes. A door-to-balloon time within 60 minutes and within the currently recommended 90 minutes was achieved in $48.9 \%$ and $78.8 \%$ of the patients respectively. The in-hospital and 30 -day mortality rates were both $3.1 \%$.

Interpretation: In a community with multiple regional hospitals and a single facility for percutaneous coronary intervention, the implementation of a multidisciplinary prehospital diagnosis and transfer pathway was feasible and resulted in most patients in the study cohort receiving primary percutaneous coronary intervention within the recommended door-to-balloon time of 90 minutes.

CMAJ 2007;176(13):1833-8

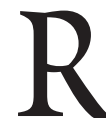

egardless of the reperfusion strategy, a shorter time from symptom onset to reperfusion in patients presenting with ST-segment elevation myocardial infarction (MI) reduces morbidity and mortality. ${ }^{1-6}$ Primary percutaneous coronary intervention is superior to thrombolytic therapy when performed expeditiously in high-volume centres. ${ }^{7-13}$ Despite evidence that primary percutaneous coronary intervention is beneficial to patients transferred from regional hospitals, delays in various aspects of the transfer process may eliminate this advantage..$^{7,814-16} \mathrm{~A}$ "door-to-balloon time" (time from arrival in the emergency department to coronary blood flow) of less than 90 minutes is recommended by the American College of Cardiology and American Heart Association ${ }^{17}$ and by the Canadian Cardiovascular Society Working Group. ${ }^{18}$ However, achieving this standard has remained elusive in most cases. ${ }^{19,20}$

We postulated that the introduction of an expedited prehospital diagnosis and transfer pathway for patients with STsegment elevation MI in a large Canadian urban centre would lead to successful treatment within the recommended doorto-balloon time. We sought, first, to determine the effect of implementation of the pathway on the delays in transferring patients from within city limits to the interventional site for primary percutaneous coronary intervention and, second, to assess the impact of the pathway on patient outcomes.

\section{Methods}

Consecutive patients with ST-segment elevation MI who received treatment with primary percutaneous coronary intervention between June I, 2004, and Oct. I, $2005(n=569)$ were considered for this study. June I, 2004, marked the full-time implementation of an expedited pre-hospital diagnosis and transfer pathway. We included patients who met the following criteria: they had symptoms of MI and presented within I2 hours after symptom onset; they were within the boundaries of the city of Calgary; they contacted Emergency Medical Services (EMS) for medical attention; and they had an ST-segment elevation of greater than $\mathrm{I}-2 \mathrm{~mm}$ in 2 consecutive leads or a left bundle branch block on the presenting electrocardiogram (ECG). We excluded patients who did not enter the transfer pathway using the EMS system $(n=199)$. We also excluded patients who activated the EMS but who were not enrolled in the pathway $(n=12)$; these I2 patients comprised 4 whose ST-segment elevation developed in the emergency department, 6 who had intermittent pain and ECG changes, and 2 who had atypical presentations. The final study cohort comprised 358 patients. The study, follow-up and reporting of data were approved by the Conjoint Ethics Review Board of the University of Calgary. 
The Foothills Interventional Cardiology Service is situated at the Foothills Medical Centre, which has 768 acute care beds. The Cardiology Service is a high-volume interventional group, with 9 interventional cardiologists. Collectively the group performs on average 2400 percutaneous coronary interventions annually, 400 of which are primary. Calgary, with a population of about 960 ooo during the study period, has 2 noninterventional hospitals involved in adult cardiology care: the Peter Lougheed Centre (5I3 acute care beds) and the Rockyview General Hospital (507 acute care beds).

Diabetes was defined as a pre-existing fasting glucose level of more than $7 \mathrm{mmol} / \mathrm{L}$, use of diabetic drugs or a new diagnosis of diabetes during the hospital stay. Hypertension was similarly determined on the basis of patients' self-reported data or use of antihypertensive medications. Cardiogenic shock was defined as blood pressure lower than $90 \mathrm{~mm} \mathrm{Hg}$ with signs of tissue hypoperfusion in the setting of a filling pressure greater than $18 \mathrm{~mm} \mathrm{Hg}$ (assessed by left ventricular end-diastolic pressure). Patients with cardiogenic shock were prescribed an inotropic agent in hospital.
For the planning of the transfer pathway, a multidisciplinary task force consisting of EMS personnel, catheterization laboratory and coronary care unit personnel, emergency physicians, quality-improvement pesonnel and cardiologists (interventional and noninterventional) was established to develop a comprehensive management model for patients with STsegment elevation MI.

In order to refine the pre-hospital diagnosis and transfer pathway, it was introduced in 3 phases. During phase I (Jan. I-May 3I, 2004) the pathway was activated between 0700 and I700 on weekdays. It consisted of rapid assessment by the EMS team, including onsite I2-lead ECG recording and interpretation, and an early alert and transfer of the patient to the nearest emergency department. Upon confirmation of the diagnosis by the emergency physician in the ambulance bay, the patient was transferred directly to the catheterization laboratory at the Foothills Medical Centre. Phase 2 (June I-Sept. 30, 2004) consisted of the same protocol executed 24 hours a day, 7 days a week.

Phase 3 (Fig. I), representing the current process, involved

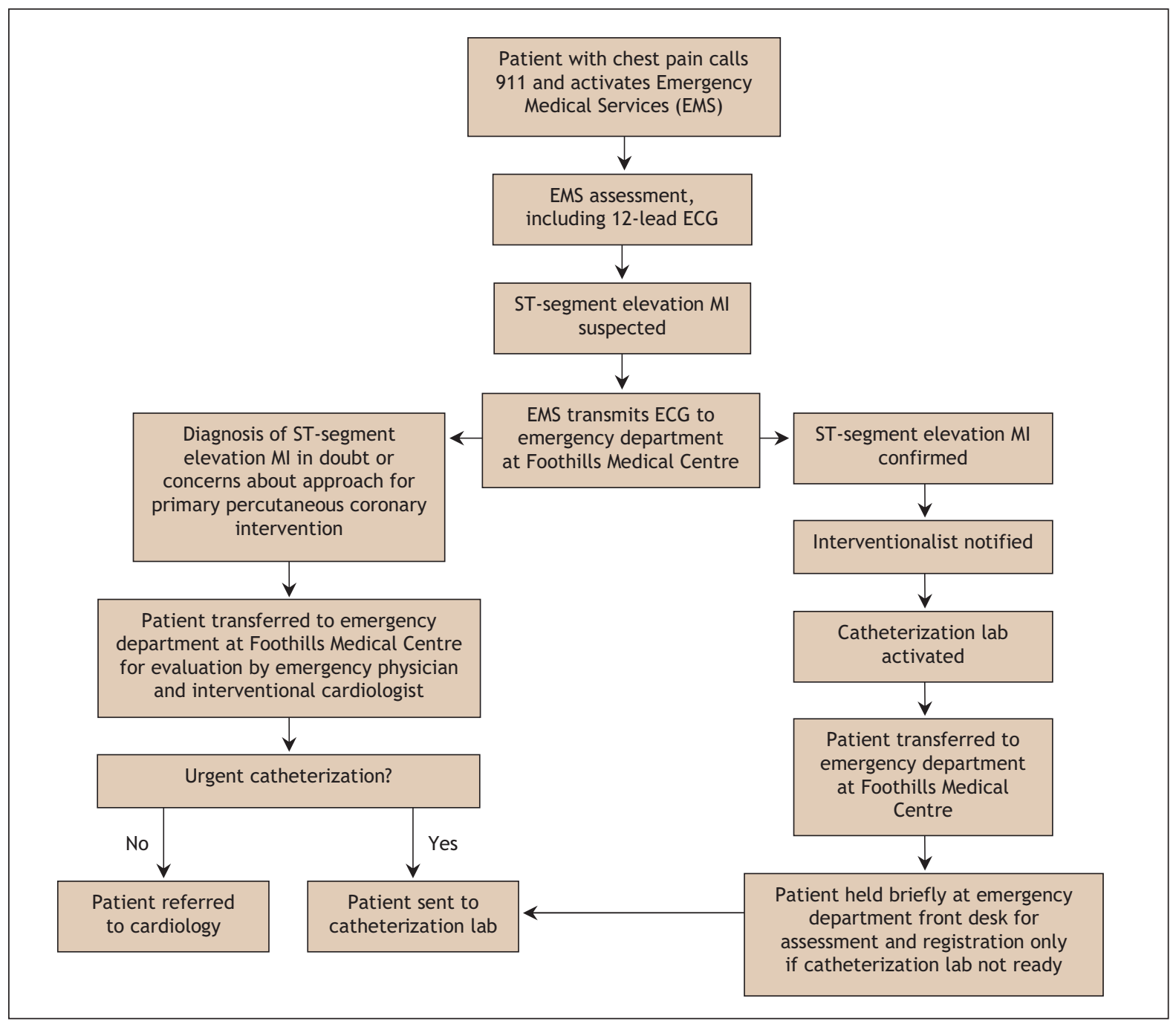

Fig. 1: Pre-hospital diagnosis and transfer pathway for primary percutaneous coronary intervention for patients with suspected ST-segment elevation myocardial infarction in the Calgary Health Region. MI = myocardial infarction, ECG = electrocardiogram. 
an onsite I2-lead ECG, which was then electronically transmitted to a central interpretation station located at the emergency department of the Foothills Medical Centre. The presence of ST-segment elevation was confirmed by the emergency physician, who then contacted the interventional cardiologist on call. This change allowed all patients with ECG changes suggestive of ST-segment elevation MI to be directly transferred by the EMS team from the scene to the interventional site at the Foothills Medical Centre.

Quality improvement of the transfer pathway was done on an ongoing basis. When door-to-balloon times were outside of the current recommendation, the process was evaluated and feedback given to care providers for education. Moving forward, data will be evaluated quarterly to determine whether further refinements are required in the various stages of the triage system.

Our primary outcome measure was door-to-balloon time in minutes. The following definitions for various time cut-points were obtained from standardized EMS documentation:

Pain to EMS: Time from patient-reported onset of sustained symptoms to arrival of EMS team. The time of the EMS call was not available, but the mean interval between EMS call to arrival is 5-1o minutes in Calgary.

EMS to emergency department: Time from arrival of EMS team on site to arrival at nearest emergency department. This represented the nearest hospital before Oct. I, 2004, and the Foothills Medical Centre after Oct. I, 2004.

Emergency department to catheterization laboratory: Time from arrival at nearest emergency department (regional hospital or Foothills Medical Centre) to arrival at catheterization laboratory.

Catheterization laboratory to flow: Time from arrival at the catheterization laboratory to coronary blood flow. Blood flow was considered present when TIMI (thrombolysis in MI) grade $2-3$ flow was observed angiographically after the lesion was crossed with the guide wire, at first balloon inflation or when flow started spontaneously.

Door-to-balloon: The sum of the times for "emergency department to catheterization laboratory" and "catheterization laboratory to flow."

EMS to flow: Time from arrival of EMS team on site to coronary blood flow at catheterization laboratory.

We also monitored length of hospital stay and major inhospital cardiac events, including death, reinfarction (defined as recurrent ischemic chest pain associated with new ST-segment elevation and re-elevation of cardiac enzyme levels to more than 2 times that at baseline), stroke, and major bleeding (defined as intracranial hemorrhage or bleeding causing hemodynamic compromise or blood transfusion, or both).

Data collection was prospective and standardized. A fulltime data manager collected information daily on all patients with ST-segment elevation MI. Standard demographic data were also obtained. The time intervals were evaluated from EMS records and catheterization laboratory logs and entered into a case report form. Information pertaining to the procedure was obtained from the catheterization laboratory record, and the chart and laboratory work were reviewed daily for complications. Patients were telephoned at I month and I year for outcomes. Vital statistic and ancillary information was coordinated through the Alberta Provincial Project for Outcomes Assessment in Coronary Heart Disease (APPROACH). The data were then entered into a secure database for subsequent analysis.

Continuous variables were expressed as mean (with standard deviation [SD]) and median (with interquartile range) values. Categorical data were expressed as counts and percentages. Correlational analysis (Pearson correlation) or unpaired Student $t$ testing was done to compare baseline clinical characteristics with door-to-balloon time (emergency department to flow). Because there were no univariable predictors of the outcome intervals, multivariable analysis was not undertaken. Because plotting of the time interval data revealed skewing to the right, values are generally reported as medians, although means are also reported. Statistical significance was considered if a 2 -sided $p$ value was less than 0.05 .

\section{Results}

The mean age of the $35^{8}$ patients was $6_{3}$ (SD I3) years, and $74.9 \%$ were men (Table I). Cardiogenic shock on presentation was present in $23(6.4 \%)$. The most common cardiac risk factor was hypertension, which was seen in $156(43.6 \%)$. Prior MI was experienced by $5 \mathrm{I}$ ( $14.2 \%$ ). Anterior MI was the most common type of infarction, occurring in 140 (39.1\%) of the patients.

Percutaneous coronary intervention was undertaken in all cases and was successful in 353 (98.6\%). A total of 473

Table 1: Baseline characteristics of 358 patients with STsegment elevation myocardial infarction who received primary percutaneous coronary intervention through an expedited pre-hospital diagnosis and transfer pathway

Characteristic

No. (\%) of patients* $n=358$

$\begin{array}{lrr}\text { Age, yr, mean (SD) } & 63.2(12.7) \\ \text { Male sex } & 268(74.9) \\ \text { Cardiogenic shock } & 23(6.4) \\ \text { Diabetes } & 50(14.0) \\ \text { Hypertension } & 156(43.6) \\ \text { Lipid profile, mmol/L, mean (SD) } & \\ \quad \text { Total cholesterol } & 4.77(1.2) \\ \quad \text { LDL cholesterol } & 2.90(1.0) \\ \quad \text { HDL cholesterol } & 1.19(0.3) \\ \quad \text { Triglycerides } & 1.63(1.4) \\ \text { Prior myocardial infarction } & 51(14.2) \\ \text { Anterior myocardial infarction } & 140(39.1) \\ \text { Prior percutaneous coronary intervention } & 26(7.3) \\ \text { Prior coronary artery bypass graft } & 6 \quad(1.7)\end{array}$

Note: $\mathrm{SD}=$ standard deviation, $\mathrm{LDL}=$ low-density lipoprotein, $\mathrm{HDL}=$ highdensity lipoprotein, $\mathrm{MI}=$ myocardial infarction.

*Unless stated otherwise. 
segments were treated, with stents placed in 346 (96.6\%) of the patients. Peri-procedural events included no reflow $(n=27)$, intra-aortic balloon pump insertion $(n=39)$, temporary pacemaker insertion $(n=\mathrm{I} 3)$, defibrillation for ventricular arrhythmias $(n=\mathrm{I} 6)$ and access-site complications $(n=3)$. All but 3 patients experienced an MI on the basis of a rise in the cardiac troponin $\mathrm{T}$ level to greater than o.I $\mu \mathrm{g} / \mathrm{L}$.

Median and mean times for the various intervals from symptom onset are shown in Table 2. The median time from EMS assessment to arrival at the emergency department (regional hospital or Foothills Medical Centre) was 35 (interquartile range 27-42) minutes. The median door-toballoon time was 62 (interquartile range $45-84$ ) minutes, with the time from arrival at the emergency department to arrival at the catheterization laboratory accounting for $32 \mathrm{~min}$ utes of this interval. The median total ischemic time, from symptom onset to coronary blood flow, was $\mathrm{I}_{3}$ (interquartile range 125-232) minutes. The median time from arrival of the EMS team on site to coronary blood flow was 97 (interquartile range 76-I24) minutes.

Fig. 2 shows the proportion of patients in whom coronary flow was achieved at various cut-points for door-to-balloon times. A door-to-balloon time of less than 90 minutes was achieved in $282(78.8 \%)$ of the patients, and of less than 60 minutes in 175 ( $48.9 \%)$. The time from arrival of the EMS team to coronary flow was less than 90 minutes for 146 (40.8\%) of the patients. No significant relation was found between any of the baseline characteristics and door-toballoon times.

Major adverse cardiac events were few (Table 3). Reinfarction, repeat revascularization, stroke, and major bleeding events occurred in less than $\mathrm{I} \%$ of the study cohort. The inhospital and 30-day mortality were both $3.1 \%$ (all of the deaths occurred in hospital), and the majority of deaths (7/II) occurred in patients who presented with cardiogenic shock.

Table 2: Mean and median time intervals (in minutes) from symptom onset to coronary blood flow

\begin{tabular}{|c|c|c|}
\hline Interval* & $\begin{array}{l}\text { Median time } \\
\text { (interquartile range) }\end{array}$ & $\begin{array}{l}\text { Mean } \\
\text { time (SD) }\end{array}$ \\
\hline $\begin{array}{l}\text { Pain to Emergency } \\
\text { Medical Services (EMS) }\end{array}$ & $53(28-120)$ & $113(182)$ \\
\hline $\begin{array}{l}\text { EMS to emergency } \\
\text { department }\end{array}$ & $35 \quad(27-42)$ & $35 \quad(12)$ \\
\hline $\begin{array}{l}\text { Emergency department } \\
\text { to catheterization } \\
\text { laboratory }\end{array}$ & $32(15-49)$ & $39 \quad(34)$ \\
\hline $\begin{array}{l}\text { Catheterization laboratory } \\
\text { to flow }\end{array}$ & $29 \quad(21-38)$ & $31 \quad(13)$ \\
\hline Pain to flow & $163(125-232)$ & 218 (189) \\
\hline EMS to flow & $97 \quad(76-124)$ & $105 \quad(41)$ \\
\hline Door to balloon $†$ & $62(45-84)$ & 71 (39) \\
\hline
\end{tabular}

*See Methods for definitions of intervals.

†"Door to balloon" is the sum of the times for "emergency department to catheterization laboratory" and "catheterization laboratory to flow."

\section{Interpretation}

For patients with ST-segment elevation MI receiving primary percutaneous coronary intervention, the introduction of a multidisciplinary pre-hospital diagnosis and transfer pathway resulted in a median door-to-balloon time of 62 (interquartile range 45-84) minutes. The recommended door-to-balloon time of less than 90 minutes was achieved in a higher proportion of patients $(79 \%)$ than has been previously reported. These results suggest that achieving reperfusion within the time recommended in recent national guidelines is feasible in major urban Canadian centres with a single interventional facility. Compared with our historical and early data from the first 2 phases of the pathway implementation, the majority of the time compression in phase 3 was achieved by shortening the interval from EMS arrival to catheterization laboratory. This was accomplished without a significant increase in the time the paramedics spent in the field making the diagnosis. Pre-hospital diagnosis and triage was key to the success of the results reported.

Current enthusiasm for primary percutaneous coronary intervention as the preferred method of reperfusion in patients with ST-segment elevation MI stems from a growing body of literature indicating the potential superiority of this strategy, even when it is necessary to transfer the patient from a regional hospital to a site with a catheterization laboratory. ${ }^{8,10,12,13,21-23}$ Unfortunately, primary percutaneous coronary intervention is achieved within the recommended time in few patients. ${ }^{19,20,24}$ The implementation of various multidisciplinary pathways to facilitate patient transfer for this procedure has been described recently. ${ }^{20,25-28}$ Protocols used by top hospitals in the United States that have achieved rapid door-to-balloon times are similar in key features to the cur-

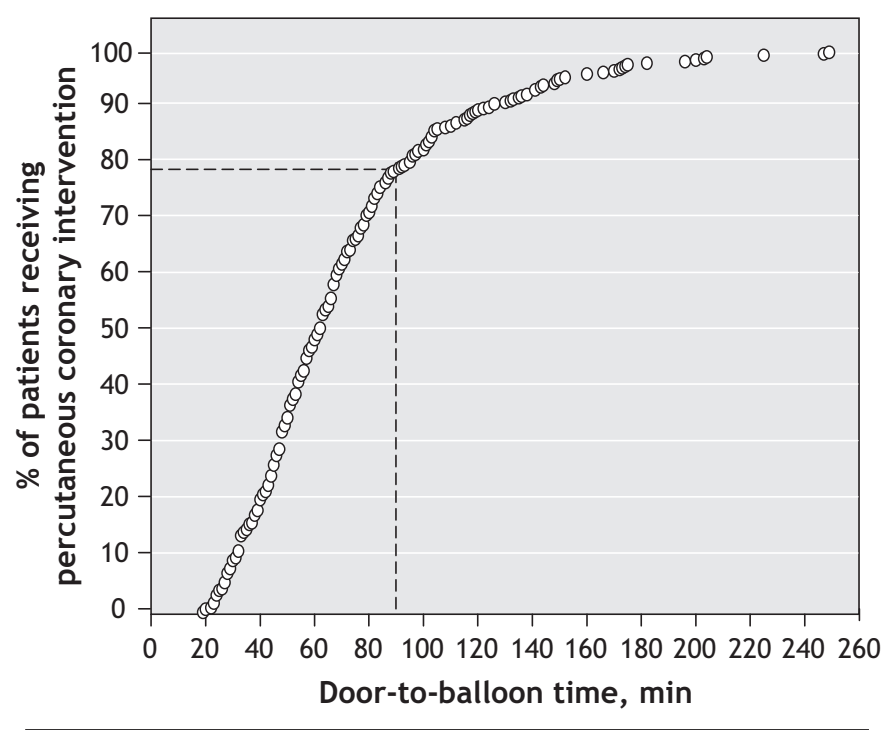

Fig. 2: Cumulative proportion of patients $\left(n=35^{8}\right)$ who received primary percutaneous coronary intervention over time (door-toballoon time) in the 16 months following the implementation of a pre-hospital diagnosis and transfer pathway in Calgary. Dotted line represents the proportion of patients in whom reperfusion was achieved within the recommended go-minute window. 
Table 3: Major in-hospital cardiac events and 30-day mortality among the 358 patients

\begin{tabular}{lc}
\hline Variable & $\begin{array}{c}\text { No. (\%) of patients* } \\
n=358\end{array}$ \\
\hline $\begin{array}{l}\text { Length of hospital stay, d, } \\
\text { median (interquartile range) }\end{array}$ & $5(4-6)$ \\
Stroke & $2(0.5)$ \\
Reinfarction & $2(0.5)$ \\
Revascularization & $3(0.8)$ \\
Major bleed & $2(0.5)$ \\
In-hospital death & $11(3.1)$ \\
Death within $30 \mathrm{~d}$ & $11(3.1)$ \\
Total no. of events & 20 \\
Total no. of patients with an event & $19(5.3)$ \\
\hline
\end{tabular}

*Unless stated otherwise.

rent pathway we have described. ${ }^{29}$ More recent registry and clinical trial data would suggest that reperfusion times might be improving. ${ }^{30,31}$ Our findings show that the establishment of a team to manage ST-segment elevation MI enhances prehospital diagnosis and facilitates the transfer of patients directly to the catheterization laboratory, as has recently been reported..$^{30}$ The concern that ECGs transmitted from the field might delay paramedic time onsite is unjustified. The use of onsite ECGs should be the standard of pre-hospital acute MI care to further reduce total ischemic times. ${ }^{32-36}$ This can be done safely and accurately. ${ }^{37}$

Our study should be interpreted in context of the following limitations. This study was not a randomized comparison between 2 approaches. However, all eligible patients with a firm suspected diagnosis of MI, including ill subjects with cardiogenic shock, were included in the analysis. In addition, we did not evaluate the use of other reperfusion strategies. Third, the transfer of patients during phase 3 directly to the interventional site, bypassing a regional hospital, will automatically reduce the door-to-balloon times. However, this is the benchmark interval upon which recommendations are made. Our median time from arrival of the EMS team to coronary blood flow was 97 minutes, which is better than that reported in most studies. Ultimately, as cases of ST-segment elevation MI are diagnosed more frequently in the field, the new standard will be diagnosis-to-flow time of less than 90 minutes.

Our findings suggest that the implementation of a multidisciplinary pre-hospital diagnosis and transfer pathway in a large urban centre with a single interventional facility is feasible and can result in most patients with ST-segment elevation MI receiving primary percutaneous coronary intervention within the recommended door-to-balloon time of 90 minutes. With the initiation of regional centres for the treatment of ST-segment elevation MI, the majority of Canadians with this condition would have direct access to percutaneous coronary intervention or alternative treatment approaches. Health care professionals treating ST-segment elevation MI should be encouraged to work together at a regional level to develop programs such as the one reported here.
This article has been peer reviewed.

From the Department of Cardiac Sciences and Libin Cardiovascular Institute, University of Calgary, Calgary, Alta.

Competing interests: None declared.

Contributors: Jacobus de Villiers was responsible for the acquisition and analysis of the data and for manuscript preparation. Todd Anderson reviewed the data and drafted the manuscript. James McMeekin reviewed the data. Raymond Leung contributed substantially to the acquisition and interpretation of the data. Mouhieddin Traboulsi was the principal investigator and performed the data analysis. All of the authors contributed substantially to the study design, revised the manuscript for important intellectual content and gave final approval of the version to be published.

Acknowledgements: We thank Amy Storm for data collection and Annie Sun for statistical analysis.

Todd Anderson is a Senior Scholar of the Alberta Heritage Foundation for Medical Research.

\section{REFERENCES}

I. Indications for fibrinolytic therapy in suspected acute myocardial infarction: collaborative overview of early mortality and major morbidity results from all randomised trials of more than rooo patients. Fibrinolytic Therapy Trialists' (FTT) Collaborative Group. Lancet I994;343:31I-22.

2. Berger PB, Ellis SG, Holmes DR Jr, et al. Relationship between delay in performing direct coronary angioplasty and early clinical outcome in patients with acute myocardial infarction: results from the global use of strategies to open occluded arteries in Acute Coronary Syndromes (GUSTO-IIb) trial. Circulation 1999;100:14-20.

3. Brodie BR, Hansen C, Stuckey TD, et al. Door-to-balloon time with primary percutaneous coronary intervention for acute myocardial infarction impacts late cardiac mortality in high-risk patients and patients presenting early after the onset of symptoms. J Am Coll Cardiol 2006;47:289-95.

4. Cannon CP, Gibson CM, Lambrew CT, et al. Relationship of symptom-onset-toballoon time and door-to-balloon time with mortality in patients undergoing angioplasty for acute myocardial infarction. JAMA 2000;283:294I-7.

5. De Luca G, Suryapranata H, Ottervanger JP, et al. Time delay to treatment and mortality in primary angioplasty for acute myocardial infarction: every minute of delay counts. Circulation 2004;109:I223-5.

6. Goldberg RJ, Mooradd M, Gurwitz JH, et al. Impact of time to treatment with tissue plasminogen activator on morbidity and mortality following acute myocardial infarction (The second National Registry of Myocardial Infarction). Am J Cardiol I998;82:259-64.

7. Vermeer F, Oude Ophuis AJ, vd Berg EJ, et al. Prospective randomised comparison between thrombolysis, rescue PTCA, and primary PTCA in patients with extensive myocardial infarction admitted to a hospital without PTCA facilities: a safety and feasibility study. Heart 1999;82:426-31.

8. Widimsky P, Budesinsky T, Vorac D, et al. Long distance transport for primary angioplasty vs immediate thrombolysis in acute myocardial infarction. Final results of the randomized national multicentre trial - PRAGUE-2. Eur Heart J 2003;24:94-I04.

9. Weaver WD, Simes RJ, Betriu A, et al. Comparison of primary coronary angioplasty and intravenous thrombolytic therapy for acute myocardial infarction: a quantitative review. JAMA I997;278:2093-8.

Io. Keeley EC, Boura JA, Grines CL. Primary angioplasty versus intravenous thrombolytic therapy for acute myocardial infarction: a quantitative review of 23 randomised trials. Lancet 2003;36r:13-20.

II. Canto JG, Every NR, Magid DJ, et al. The volume of primary angioplasty procedures and survival after acute myocardial infarction. National Registry of Myocardial Infarction 2 Investigators. N Engl J Med 2000;342:1573-80.

I2. Grines C, Patel A, Zijlstra F, et al. Primary coronary angioplasty compared with intravenous thrombolytic therapy for acute myocardial infarction: six-month follow up and analysis of individual patient data from randomized trials. Am Heart $J$ 2003; I45:47-57.

13. Zijlstra F. Angioplasty vs thrombolysis for acute myocardial infarction: a quantitative overview of the effects of interhospital transportation. Eur Heart $J$ 2003;24:2I-3.

I4. Widimsky P, Groch L, Zelizko M, et al. Multicentre randomized trial comparing transport to primary angioplasty vs immediate thrombolysis vs combined strategy for patients with acute myocardial infarction presenting to a community hospital without a catheterization laboratory. The PRAGUE study. Eur Heart J2000;2I:823-3I.

I5. Grines CL, Westerhausen DR Jr, Grines LL, et al. A randomized trial of transfer for primary angioplasty versus on-site thrombolysis in patients with high-risk myocardial infarction: the Air Primary Angioplasty in Myocardial Infarction study. $J$ Am Coll Cardiol 2002;39:1713-9.

I6. Andersen HR, Nielsen TT, Rasmussen K, et al. A comparison of coronary angioplasty with fibrinolytic therapy in acute myocardial infarction. $N$ Engl J Med 2003;349:733-42.

17. Antman EM, Anbe DT, Armstrong PW, et al. ACC/AHA guidelines for the management of patients with ST-elevation myocardial infarction-executive summary: a re- 
port of the American College of Cardiology/American Heart Association Task Force on Practice Guidelines (Writing Committee to Revise the I999 Guidelines for the Management of Patients With Acute Myocardial Infarction). Circulation 2004;IIO:588-636

I8. Armstrong PW, Bogaty P, Buller CE, et al. The 2004 ACC/AHA Guidelines: a perspective and adaptation for Canada by the Canadian Cardiovascular Society Working Group. Can J Cardiol 2004;20:1075-9.

I9. Nallamothu BK, Bates ER, Herrin J, et al. Times to treatment in transfer patients undergoing primary percutaneous coronary intervention in the United States: National Registry of Myocardial Infarction (NRMI)-3/4 analysis. Circulation 2005;III:76I-7.

20. McNamara RL, Herrin J, Bradley EH, et al. Hospital improvement in time to reperfusion in patients with acute myocardial infarction, I999 to 2002. J Am Coll Cardiol 2006;47:45-5I.

2I. Baks T, van Geuns RJ, Biagini E, et al. Effects of primary angioplasty for acute myocardial infarction on early and late infarct size and left ventricular wall characteristics. J Am Coll Cardiol 2006;47:40-4.

22. Nallamothu BK, Antman EM, Bates ER. Primary percutaneous coronary intervention versus fibrinolytic therapy in acute myocardial infarction: Does the choice of fibrinolytic agent impact on the importance of time-to-treatment? Am J Cardiol 2004;94:772-4.

23. Jacobs AK. Primary angioplasty for acute myocardial infarction: Is it worth the wait? NEngl J Med 2003;349:798-800.

24. Fox KA. An international perspective on acute coronary syndrome care: insights from the Global Registry of Acute Coronary Events. Am Heart J 2004;I48:S40-5.

25. Henry TD, Unger BT, Sharkey SW, et al. Design of a standardized system for transfer of patients with ST-elevation myocardial infarction for percutaneous coronary intervention. Am Heart J 2005; $150: 373-84$

26. Bradley EH, Roumanis SA, Radford MJ, et al. Achieving door-to-balloon times that meet quality guidelines: How do successful hospitals do it? J Am Coll Cardiol 2005;46:I236-4I.

27. Olivari Z. Hospital networks for the treatment of acute myocardial infarction. Ital Heart $J 2005 ; 6: 459-64$

28. Waters RE, Singh KP, Roe MT, et al. Rationale and strategies for implementing community-based transfer protocols for primary percutaneous coronary intervention for acute ST-segment elevation myocardial infarction. J Am Coll Cardiol 2004;43:2153-9.

29. Bradley EH, Curry LA, Webster TR, et al. Achieving rapid door-to-balloon times: how top hospitals improve complex clinical systems. Circulation 2006;113:1079-85.

30. Le May MR, Davies RF, Dionne R, et al. Comparison of early mortality of paramedic diagnosed ST-segment elevation myocardial infarction with immediate transport to a designated primary percutaneous coronary intervention center to that of similar patients transported to the nearest hospital. Am J Cardiol 2006;98:1329-33.

3I. Stenestrand U, Lindback J, Wallentin L. Long-term outcome of primary percutaneous coronary intervention vs prehospital and in-hospital thrombolysis for patients with ST-elevation myocardial infarction. JAMA 2006;296:1749-56.

32. Sekulic M, Hassunizadeh B, McGraw S, et al. Feasibility of early emergency room notification to improve door-to-balloon times for patients with acute ST segmen elevation myocardial infarction. Catheter Cardiovasc Interv 2005;66:316-9.

33. Canto JG, Rogers WJ, Bowlby LJ, et al. The prehospital electrocardiogram in acut myocardial infarction: Is its full potential being realized? National Registry of Myocardial Infarction 2 Investigators. J Am Coll Cardiol r997;29:498-505.

34. Karagounis L, Ipsen SK, Jessop MR, et al. Impact of field-transmitted electrocar diography on time to in-hospital thrombolytic therapy in acute myocardial infarction. Am J Cardiol I990;66:786-9I.
35. Kereiakes DJ, Gibler WB, Martin LH, et al. Relative importance of emergency medical system transport and the prehospital electrocardiogram on reducing hospital time delay to therapy for acute myocardial infarction: a preliminary report from the Cincinnati Heart Project. Am Heart J I992;123:835-40.

36. Curtis JP, Portnay EL, Wang Y, et al. The pre-hospital electrocardiogram and time to reperfusion in patients with acute myocardial infarction, 2000-2002: findings from the National Registry of Myocardial Infarction-4. J Am Coll Cardiol 2006;47:I544-52.

37. Le May MR, Dionne R, Maloney J, et al. Diagnostic performance and potential clinical impact of advanced care paramedic interpretation of ST-segment elevation myocardial infarction in the field. CJEM 2006;8:40I-7.

Correspondence to: Dr. Mouhieddin Traboulsi, University of Calgary, Foothills Interventional Cardiology Service, Foothills Medical Centre, Rm. C807, I403-29th St. NW, Calgary AB T2N 2T9; trabouls@ucalgary.ca

\section{Members of the Foothills Interventional Cardiology Service:} Arun Abbi, Emergency Physician; Dwayne Clayden, Emergency Medical Services Leader; Karen Foudy, Assistant Patient Care Manager, Coronary Care Unit; Teresa Davidson, Assistant Patient Care Manager, Emergency Department; Linda Fundytus, Catheterization Laboratory Nurse Manager; Jamie Jones, Quality Improvement Consultant for Emergency Department; Victor Jordan, Emergency Department Telemedicine Physician Coordinator; Debra Lundberg, Interventional Cardiology Research Nurse; Alexis Magneau, Instructor for Emergency Department; James McMeekin, Quality Improvement Physician for Cardiac Sciences; Glenn McRae, Quality Improvement Consultant for Emergency Department; Tanis Rollefstad, Quality Improvement Consultant for Cardiac Sciences; Tom Rich, Quality Improvement Physician for Emergency Department; Lana Shewchuk, Foothills Interventional Cardiology Coordinator; Amy Storm, Acute Myocardial Infarction Data Base Coordinator; Mouhieddin Traboulsi (principal investigator), Director of Catheterization Laboratory; Linda Walters, Assistant Patient Care Manager, Rockyview General Hospital Emergency Department Members of the Calgary STEMI QIHI Group: Todd Anderson, François Charbonneau, Michael Curtis, David Goodhart, James Ronak Kanani, Merril Knudtson, Frank Spence, Mouhieddin Traboulsi

\section{Holiday Review 2007 Call for submissions}

Hilarity and good humour ... help enormously in both the study and the practice of medicine ... [I]t is an unpardonable sin to go about among patients with a long face. - William Osle

Quirky, contentious or simply fun - we want it all! Yes, it's time to send us your creative missives for CMA's Holiday Review 2007. We're looking for humour, spoofs, punchy personal reflections and off-beat scientific explorations.

Please submit online (at http://mc.manuscriptcentral.com/cmaj). Articles should be no longer than 1200 words; photographs and illustrations are welcome. Mention in your cover letter that your submission is intended for this year's Holiday Review.

The deadline for submissions is Oct. 1, 2007.

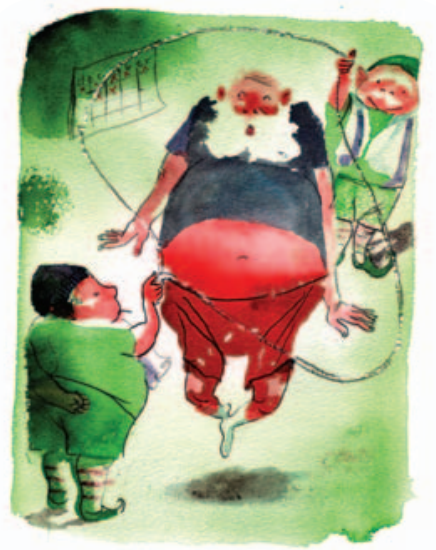

